\title{
THE IMPACT OF TRAINING SURFACE IN AGILITY OF PREPUBESCENT VOLLEYBALL
} PLAYERS

\author{
E. Gortsila ${ }^{1}$, A. Theos ${ }^{1}$, G. Nesic ${ }^{2}$, M. Maridaki ${ }^{1}$ \\ ${ }^{I}$ Sports Medicine \& Biology of Exercise, University of Athens, Athens, Greece, ${ }^{2}$ Sport and Physical \\ Education, University of Belgrade, Belgrade, Serbia
}

The purpose of the present study was to examine the impact of training surface in agility of prepubescent volleyball players. Thirty female prepubescent volleyball players (age: $11.2 \pm 0.6 y r s$ ) took part in this study and were randomly allocated in two groups. Group A $(\mathrm{N}=15)$ participated in a 10 week training programme in sand surface, while group B $(\mathrm{N}=15)$ participated in a same programme in land surface. Measurements of agility (T-Test \& Illinois) were conducted before (pre) and after (post) the training period. Subjects performed the agility tests on the land (L condition) and on the sand (S condition). Differences in agility pre - post training, between the conditions and between the groups were analysed using T-test. Agility T-Test and Illinois did not differ significantly in both groups in pre condition, but were significantly improved in post $(\mathrm{p}<0.001)$. Group $\mathrm{A}$ achieved greater improvement in T-Test in both $\mathrm{L}$ and $\mathrm{S}$ condition compared to group $B$ ( $S$ condition: $A=15.0 \pm 0.1$ vs. $B=17.2 \pm 0.2 \mathrm{sec}, \mathrm{p}<0.0001$ and $L$ condition: $A=13.2 \pm 0.1$ vs. $B=$ $14.4 \pm 0.1 \mathrm{sec}, \mathrm{p}<0.0001$ ). In accordance were the results for Illinois test ( $\mathrm{S}$ condition: $\mathrm{A}=21.4 \pm 0.2 \mathrm{vs}$. $\mathrm{B}=$ $22.3 \pm 0.1 \mathrm{sec}, \mathrm{p}<0.0001$ and $\mathrm{L}$ condition: $\mathrm{A}=20.2 \pm 0.1 \mathrm{vs} . \mathrm{B}=21.1 \pm 0.2 \mathrm{sec}, \mathrm{p}<0.0001)$. Despite the fact that agility was improved in both groups after the 10- week training program, the much greater improvement achieved in group A suggest that the training surface may play an important role. 